\title{
Impacts of Psychological Capital on the Ethical Behavior of Teachers: A Case of Educational Sector in Pakistan
}

\author{
Fazal ur Rehman ${ }^{1,}{ }^{*}$, Rosman Bin Md Yusoff ${ }^{2}$, Shafie Bin Mohamed Zabri ${ }^{3}$, and Fadillah Binti Ismail ${ }^{4}$ \\ 1,3,4 FPTP, Universiti Tun Hussein Onn Malaysia, Parit Raja, Johor, Malaysia \\ ${ }_{2}^{2}$ PPUK, Universiti Tun Hussein Onn Malaysia, Parit Raja, Johor, Malaysia
}

\begin{abstract}
This study aims at investigating the effect of psychological capital on the ethical behavior of teachers in the higher educational sector of Pakistan. This study applied quantitative approach to collect data through questionnaire based survey from the teaching staff of Rawalpindi and Islamabad region universities in Pakistan. This study used descriptive statistics and step wise regression to analyze the collected data. Results of the study indicate that psychological capital has positive and statistically significant effect on the ethical behavior of teachers in the higher educational sector of Pakistan. This study addresses the need to investigate the relationship of psychological capital with the ethical behavior of teachers in the higher educational sector of Pakistan, which can help in understanding the nature of these variables in the higher educational sector of Pakistan.
\end{abstract}

Keywords: Psychological Capital, Ethical Behavior, Teachers, Pakistan

\section{Introduction}

Teachers are the key assets of every educational organization and may influence the goals and objectives of organizations in positive or negative ways. The professional attitude and ethical behavior of teachers may influence on the careers and learning level of students. Their behavior with students and as a whole in organization may lead to gain competitive advantage and may enhance the level of learning and universities standard as well. However, psychological capital is one of the factors that may cause of enhancing the ethical behavior of teachers in universities. According to [1] psychological capital is "a core psychological factor of positivity in general, and positive organizational behavior (POB) meeting states in particular, that go beyond human and social capital to gain a competitive advantage through investment / development of "who you are". However, previous literature has mentioned some key factors of psychological capital that are; self-efficacy, hope, optimism and life orientation [2]. These factors may affect the performance of teachers and help in behaving ethically in universities. As, [3] have assumed that psychological capital is helpful in developing positive attitude and professional skills of behaving in working environment.

On the other hand, ethical behavior may one of the interesting techniques to successfully accomplish the

\footnotetext{
*Corresponding author: fazal_marwatpk@yahoo.com
}

objectives of organization. Ethics are the code of conduct or a set of principles in a working environment to assess right or wrong imagination [4]. These codes of conduct may help in developing a culture of behaving in organizations. The predefined ethical principles may help in executing working environment in efficient ways. Therefore, this study has interest to investigate whether psychological capital has any relationship with the ethical behavior of teachers in Rawalpindi and Islamabad region universities in Pakistan or not? For the aim, a study was conducted in the higher educational sector of Pakistan to assess the relationship between psychological capital and ethical behavior of teachers in Rawalpindi and Islamabad region of Pakistan.

\section{Literature Review}

\subsection{Psychological Capital}

The term psychological capital originated in the field of economics and sociology to stare the performance at workplace and may cause of influence in behaving. The presumed behavior may cause confidence and self-esteem in employees [5]. However, this conception led towards development of "Positive Psychological Capital" in economics literature. Simply, it is known as psychological capital along with some key factors that are; "(a) Paradigm of positive psychology that highlights the 
significance of positivity and strength, (b) Positive organizational behavior, (c) Human and social capital i.e. what you know, who you know, who you are, (d) Investment and development for getting improvement in performance that may result in competitive advantage" [1]. Therefore, psychological capital is an optimistic approach of individual along with some features like; selfefficacy, hope, optimism and resiliency. These characteristics are described as;

\subsubsection{Self-Efficacy}

Self-efficacy is the comparison of thinking's, feelings and actions of individual in different situations to handle problematic situations [6]. Likewise, [7] have defined self-efficacy as the "individual's conviction... about his or her abilities to mobilize the motivation, cognitive resources, and courses of action needed to successfully execute a specific task within a given context". Therefore, low self-efficacious individual may face problems in challengeable tasks as compared to higher self-efficacious individual [8]. However, literature has mentioned some interesting features of self-efficacious individuals to distinguish them from others like, they often set demandable tasks for themselves, welcome challenges, possess higher level of self-motivation, have energy for completing goals and insists to problematic situations [9]. These features may provide sagacity to teachers to perform in efficient ways. Individuals with these features may not delay in demanding tasks and are called as "discrepancy reduction" as they develop discrepancies in unbreakable loops in attaining the tasks. They may have high level of confidence and repetition of failures or negative feedback has no influence on their minds [10].

\subsubsection{Hope}

Hope is the well-known term in daily life and is "the belief that one can find pathways to desired goals and become motivated to use those pathways" [11]. According to [12], hope is "a positive motivational state that is based on an interactively derived sense of successful (a) agency (goal-oriented energy) and (b) pathways (planning to meet goals)". However, [9] have noted that a lack of research in the term hope and its influence in working environment. Management that posses' high level hope is often perceived to perform well and will provide satisfactory working environment to employees [13]. However, [14] have linked it with job satisfaction and commitment towards organization. Likewise, [15] have differentiated hope from the other elements of psychological capital and assumed that it is theoretically a convergent element. Whereas, [16] have verified hope as the element with discriminate validity as compared to other elements of psychological capital.

\subsubsection{Optimism}

Tiger [17] has highlighted the conception of optimism and proposed a definition as "a mood or attitude associated with an interpretation about the social or material- one which the elevator regards as socially desirable to his or her advantage, or for his or her pleasure". Precisely, optimists are "those people who make internal, stable, attributions regarding positive events (e.g. task accomplishment) and those who attribute external, unstable, and specific reasons for negative events (e.g., a missed deadline)". Optimism is a vigorous and unchangeable open process and comprises of three steps that are; "leniency for the past, gratitude for the present and opportunity for future" $[18,19]$. Therefore, optimism is a key element of psychological capital and cause of motivation and emotions [20]. Hence, optimism may have influence on the decisions and behavior of teachers to keep them involved in getting work done.

\subsubsection{Resilience}

Resilience is "the positive psychological capacity to rebound, or 'bounce back' from adversity, uncertainty, conflict, failure, or even positive change, progress and increased responsibility". According to [1] resilient people having abilities to "(a) a staunch acceptance of reality, (b) a deep belief, often buttressed by strongly held values, that life is meaningful, and (c) an uncanny ability to improvise and adapt to significant change". However, [21] have expressed their opinions that resilient people are efficient in getting work done and may be able to adjust themselves in threaten situations. [22] have noted lacks of knowledge in the term resilience but researchers are busy at various level to explore it, like; positive use of emotions, change in personal status [23], improvement in efficiency [24], building sense of honesty and reality [25]. For example, [22] have assumed that positive emotions are the sources to get improvement in resilience.

\subsection{Ethical Behavior}

Ethical behavior may be the moral and professional set of principles in an organization for developing its culture and a set of executing regulation. These predefined principles may help to understand right and wrong perception of behaving in organization. Likewise, [4] has expressed his opinions that ethics are the set of principles to estimate the right and wrong indication in an organization and helps in developing acceptable culture of behaving. Therefore, ethical behavior may be used as a tool to assess the performance of employees and may affect the operation of a business. Sometime unethical behavior may be used as a tool to assess the ethical behavior of employees in an organization [26]. The study has heighted the conception the sometime unethical behavior can create confusion for management due to lack 
of predefined principles. Therefore, companies are defining ethical standard and strategies to smoothly execute the business operations, but the implementation may quit rare due to shortage of time.

\subsection{Theoretical Framework}

Considerable attention has been given towards behavioral aspects of employees, psychological capital and its role in organizations [26]. [9] have shown their intentions to explore various aspects of organizational behavior and psychological capital in organizational context. However, [27] have noted lack of researchers' interest in psychological capital as compared to organizational behavior. The study assumed that psychological capital can enhance the perceptions of organizational behavior. [28] has observed that positive emotions can lead to behave positively in organization. [29] have assessed the relationship of psychological capital with organizational citizenship behavior and organizational commitment in Indian context. Later on, [30] have assessed the relationship of psychological capital with organizations ethical climate components in Iranian context. At the same time, [31] have assessed the association of mediation in psychological capital with organizational climate and organizational citizenship behavior in Pakistani context. Meanwhile, [32] have conducted an empirical study to assess the relationship of organizational support with the ethical behavior. [26] have assessed the relationship of psychological capital with the ethical behavior of sales force in the Telecom Sector. The study suggested investigating the relationship of psychological capital with the ethical behavior in service as well as manufacturing industries. However, previous literature has mentioned psychological capital and its relationship with several other factors like job satisfaction, organizational citizenship behavior and ethical behavior in sales department. Hence, this study has interest to assess the relationship of psychological capital with the ethical behavior of teachers in Pakistani universities. Therefore, the current study is using the theoretical model of [26] to assess the relationship between variables in the higher educational sector of Pakistan.

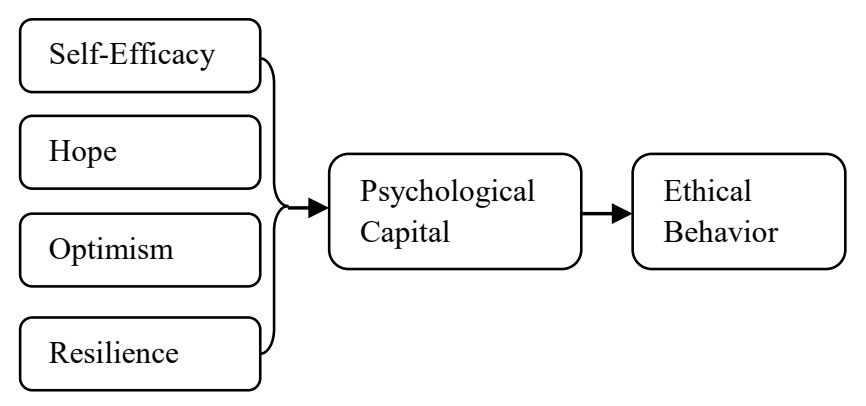

Figure 1 Rehman et al (2014) conceptual model

\subsection{Hypothesis of the Study}

Hypotheses are the predictions of the study that may be true or false and based on the theoretical concept of previous literature. Results will verify the developed hypothesis in this study as analyzed results decides to accept or reject the developed hypothesis [33]. This study has the following hypothesis;

H1: Self-efficacy has positive relationship with the ethical behavior of teachers.

H2: Hope has positive relationship with the ethical behavior of teachers.

H3: Optimism has positive relationship with the ethical behavior of teachers.

H4: Resilience has positive relationship with the ethical behavior of teachers.

\section{Methodology}

This study applied quantitative approach to collect data through questionnaires based survey form the faculty members of public and private sector universities in Rawalpindi and Islamabad region of Pakistan. Most of the respondents were below the age of 40 years. The measuring instrument was comprised of demographic features of respondents and information about other variables of the study. It was made clear to the respondents that the collected data will be used for research purposes only and will be kept as confidential. The instrument of the study was adopted from previous studies $[26,34,35]$. A pilot study was conducted to assess the reliability of adopted instrument. For the purpose, the study collected data from 60 respondents which included both gender male and female. The following table shows the result of pilot study;

Table 1. Value of Cronbach Alpha of Pilot Study

\begin{tabular}{|l|l|l|}
\hline Variables & No of Items & Value of Cronbach Alpha \\
\hline SE & 10 & 0.721 \\
\hline HP & 6 & 0.730 \\
\hline OP & 8 & 0.746 \\
\hline RS & 10 & 0.791 \\
\hline EB & 11 & 0.732 \\
\hline \multicolumn{2}{|l|}{} & \\
\hline *SE - Self Efficacy, * HP - Hope, *OP - Optimism, \\
*RS - Resilience, *EB - Ethical Behavior \\
\hline
\end{tabular}

After getting the aim of reliability, the study collected data for finding the relationship between main variables. 
The collected data was analyzed by using correlation and regression statistic to find statistical results of the study.

\section{Results}

After data collection, the study applied correlation statistics to determine the association between variables. The results of correlation statistics are presented in the following table;

Table 2. Means, Standard Deviation, and Correlation between Variables

\begin{tabular}{|c|c|c|c|c|c|c|c|}
\hline & $\begin{array}{l}\text { Mean } \\
\text { s }\end{array}$ & St. D & $\overline{\mathbf{S E}}$ & HP & OP & RS & EB \\
\hline$\overline{\mathrm{SE}}$ & 1.4315 & .42144 & 1 & & & & \\
\hline$\overline{\mathrm{HP}}$ & 2.0219 & .33208 & .041 & 1 & & & \\
\hline $\mathrm{OP}$ & 1.6401 & .32914 & .047 & $.051 *$ & 1 & & \\
\hline$\overline{R S}$ & 1.5231 & .48412 & $.031 *$ & $.032 *$ & .049 & 1 & \\
\hline EB & 2.0041 & .29415 & $.030 *$ & .019 & $.051 *$ & .062 & 1 \\
\hline \multicolumn{8}{|c|}{$\begin{array}{l}\text { *Correlation is significant at the } 0.05 \text { level (2-tailed), }{ }^{* *} \text {. Correlation is significant } \\
\text { at the } 0.01 \text { level (2-tailed). }\end{array}$} \\
\hline
\end{tabular}

Results of correlation statistics in the above table indicates that self-efficacy has positive relationship with hope, optimism, resilience and the ethical behavior of teachers in the higher educational sector of Pakistan. Hope is positively correlated with resilience, optimism and ethical behavior of teaching staff. Similarly, optimism is also positively correlated with resilience and the ethical behavior of teachers in the higher educational sector of Pakistan. Likewise, resilience is positively correlated with the ethical behavior of teachers in the educational sector in Rawalpindi and Islamabad region of Pakistan.

The study applied step wise regression to determine the statistical results of the study. This is the interesting part of study to identify the effect of psychological capital on the ethical behavior of teachers in the higher educational sector of Pakistan. The following table indicates the statistical results of regression analysis;

Table 3. Regression Analysis between Psychological Capital and Ethical behavior

\begin{tabular}{|l|l|l|l|}
\hline & Beta Value & $\begin{array}{l}\text { Standard } \\
\text { Error }\end{array}$ & P Value \\
\hline SE & .360 & .035 & .004 \\
\hline HP & .341 & .031 & .004 \\
\hline OP & .437 & .024 & .001 \\
\hline RS & .591 & .040 & .003 \\
\hline
\end{tabular}

\section{$* * \mathrm{P}<0.01, * \mathrm{P}<0.05$}

The above table indicates the result of regression and the magnitude of psychological capital (Self-efficacy, hope, optimism and resilience) on the ethical behavior of teachers in the higher educational sector of Pakistan. The table indicates that all the sub dimensions of psychological capital have positive influence on the ethical behavior of teachers. The values of beta coefficient of self-efficacy $(\beta=0.360)$, the value of beta coefficient for hope is $(\beta=0.341)$, for optimism $(\beta=$ $0.437)$ and for resilience is $(\beta=0.591)$. Therefore, the results lead to the conclusion that psychological capital has positive and significant effect on the ethical behavior of teachers. It can be inferred that teachers in the higher educational sector of Pakistan may be able to handle the problems due to sufficient knowledge and skills. It can be inferred from the results that self-efficacy has positive influence on the ethical behavior of teachers as they may be able to handle the problematic situations independently. Similarly, it can be said that hope has positive effects on the ethical behavior of teachers as they may able to effectively accomplish their life objectives. Likewise, it can be inferred that optimism has also positive influence on the ethical behavior of teachers as they may be able to show positive attitude in different situations. It can also be said that resilience has positive effect on the ethical behavior of teachers as they may be able to adjust themselves in threaten situations. Therefore, all the dimensions of psychological capital have positive effects on the ethical behavior of teachers and leads to the conclusion to accept all the hypothesis of study.

\section{Discussion}

This study has investigated the impact of psychological capital on the ethical behavior of teachers in the higher educational sector of Pakistan. This study has applied quantitative approach to collect data through questionnaires based survey from the faculty members of both public and private sector universities in Rawalpindi and Islamabad region of Pakistan. The results of the study indicate that all the dimensions of psychological capital have positive and significant effects on the ethical behavior of teachers in the higher educational sector of Pakistan. The results of this study are supported by [26]. The results of this study are in line to with some previous studies which are mentioned as follow.

Golparvar and Azarmonabadi [30] have conducted a study to investigate the relationship of psychological capital with the components of ethical climate in Iranian context. The study distributed questionnaires among the railway employees in Isfahan city to collect data. The results of the study have shown a positive and statistically significant relationship between psychological capital and the components of ethical climate. This study is in line in 
the term of psychological capital. Likewise, [31] have conducted a study to assess the relationship between the mediation of psychological capital and organizational climate, organizational citizenship behavior in Pakistani context. The study has collected data from the 108 employees of multinational companies through questionnaire based survey. The results of the study have shown that psychological capital has significant effect on organizational climate and organizational citizenship behavior. In the same manner,

[36] has conducted a study to investigate the relationship of emotional intelligence, organizational commitment and job satisfaction with the ethical behavior of employees in Chinese context. The study has found a positive and significant relationship among main variables. It has noted that age has significant but negative influence on the ethical behavior of Chinese employees. This study is in line in the sense of ethical behavior. However, the managerial aspects of the study were to assess whether psychological capital has any relationship with the ethical behavior of teachers in the higher educational sector of Pakistan. The results of this study have contributed in the existing knowledge that psychological capital can be applied to influence the ethical behavior of teachers in the higher educational sector of Pakistan. The results of this study imply that educational institute can focus their efforts on the teacher's individual factors "psychological capital" to enhance the standard of ethical behavior in educational environment. The educational institutes can provide special training and practices to enhance the level of psychological capital for building smooth ethical environment. The educational institutes can establish special counters to handle the personal issues of teachers to monitor the display of unethical behavior educational environment.

\section{Conclusion}

This study aims at investigating the effect of psychological capital on the ethical behavior of teachers in the higher educational sector of Pakistan. The study collected data through questionnaire based survey from the faculty members in both public and private sector universities in Rawalpindi and Islamabad region of Pakistan. The collected data were analyzed via correlation and step wise regression to determine statistical results of the study. The results indicate that psychological capital has positive and significant effect on the ethical behavior of teachers in the higher educational sector of Pakistan. Therefore, while interpreting the results of the study it should be kept in mind that the data was collected from a small region of Pakistan and readers need to be cautious in generalizing the results of this study. This study is only limited to the higher educational sector of Pakistan within two cities only and future study should include manufacturing sector and addition of moderating variables like gender as well. This study has also a deficiency as it excluded the primary and secondary level of education and the future studies can assess psychological capital of the teachers in lower educational level.

\section{References}

1. Fred, L., Carolyn, M. Y. Human, Social, and now positive psychological capital management, investing in people for competitive advantage, Organizational Dynamics 33. 2, 143-160 (2004)

2. Fred, O. W., Fred, L., James, B. A., Adegoke, O. Authentically leading groups: The mediating role ofcollective psychological capital and trust, Journal of Organizational Behavior 32. 1, 4-24 (2011)

3. Fred, L., Steven, M. N., Bruce, J. A., James, B. A. The mediating role of psychological capital in the supportive organizational climate-employee performance relationship, Journal of Organizational Behavior 29. 2, 219-238 (2008)

4. Hamza, A. Ethical Perceptions of Public-Sector Employees and Citizens and their Impact upon Attitudes against Unethical Behavior, Turkish Studies 13.1, 27-44 (2012)

5. Arthur, H. G., Jonathan, R. V., William, D.J.R. The Impact of Psychological and Human Capital on Wages, Economic Inquiry 35, 813-821 (1997)

6. Albert, B. Health promotion from the perspective of social cognitive theory, Psychology and Health 13, 623-649 (1998)

7. Alexander, D. S., Fred, L. Self-Efficacy and Work-Related Performance: A Meta-Analysis, Psychological Bulletin 124.2, 240-261 (1998)

8. Albert, B. An agentic perspective on positive psychology In S. J. Lopez (Ed.) Positive psychology: Exploring the best in people (167196). Westport, CT: Greenwood Publishing 1, (2008)

9. Fred, L., Bruce, J. A., James, B.A., Steven, M. N. Positive Psychological Capital: Measurement and Relationship with Performance and Satisfaction, Personnel Psychology 60, 541-572 (2007)

10. Albert, B., Edwin, A. L. Bandura, A., Locke, E. A. Negative self-efficacy and goal effects revisited, Journal of Applied Psychology 88. 1, 87-99 (2003)

11. Snyder, C. R., Lopez, S. J. Handbook of Positive Psychology, Oxford, UK: Oxford University Press. 257- 276 (2002)

12. Charles, R. S., Donlson, R.F (Eds.), Handbook of social and clinical psychology: The health perspective (285-305). Elmsford, NY: Pergamon (1991) 
13. Suzanne, J. P., Fred, L. The positive impact and development of hopeful leaders, Leadership and Organizational Development Journal 24, 26-31 (2003)

14. Fred, L., Susan, M. J. Hope: A new positive strength for human resource development, Human Resource Development Review 1, 30422 (2002)

15. Charles, R. S. Hope theory: Rainbows in the mind". Psychological Enquiry 13. 4, 249-276 (2002)

16. James, C., Lauren, R. Construct validities and the empirical relationships between optimism, hope, self-efficacy, and locus of control, Work. 19.2, 125-136 (2002)

17. Tiger, L. Optimism: The Biology of hope, New York: Simon \& Schuster (1971)

18. Peterson, C. The future of optimism, American Psychologist 55. 1, 44-55 (2000)

19. Schneider, S.I. In search of realistic optimism, American Psychologist, 56. 3, 250-263 (2001)

20. Luthans, F. The need for and meaning of positive organizational behavior, Journal of Organizational Behavior 23. 6, 695-706 (2002a)

21. Block. J., Kremen. A.M. IQ and ego-resiliency: Conceptual and empirical connections and Separateness, Journal of Personality and Social Psychology 70.2, 349-361 (1996)

22. Tugade, M. M., Frederickson, B. L. Resilient individuals use positive emotions to bounce back from negative emotional experiences, Journal of Personality and Social Psychology 86. 2 ,320333 (2004)

23. Masten, A.S. Ordinary Magic: Resilience processes in development, American Psychologist 56. 3, 227-239 (2001)

24. Luthans, F., Avey, J. B., Avolio, B. J., Norman, S. M., Combs, G. M. Psychological capital development: toward a micro intervention, Journal of Organizational Behavior. 27. 3, 387393 (2006)

25. Couty, D.L. How resilience works, Harvard Business Review 80.3, 46-55 (2002)

26. Rehman, F.U., Javed, F., Rehman, S., Nawaz, T. Determining the Influence of Psychological Capital on the Ethical Behavior of Sales Force: A Case of Telecom Sector, European Journal of Business and Management, 6.37, 290-296 (2014)
27. Luthans, F., Avolio, B. J., Avey, J. B., Norman, S. M. Positive psychological capital: Measurement and relationship with performance and satisfaction, Personnel Psychology 60. 3, 541-572 (2007)

28. Fredrickson, B.L., Joiner, T. Positive emotions trigger upward spirals toward emotional wellbeing, Psychological Science 13, 172-175 (2002)

29. Shahnawaz. M.G., Jafri. H. Psychological Capital as Predictors of Organizational Commitment and Organizational Citizenship Behavior, Journal of the Indian Academy of Applied Psychology 35, 78-84 (2009)

30. Golparvar. M., Azarmonabadi. A. R. Explaining Psychological Capital Components Through Organization's Ethical Climate Components, International Journal of Business, Economics and Management 1 .8, 216-228 (2014)

31. Faisal, Q., Hina, J. Mediation of Psychological Capital between Organizational Climate and Organizational Citizenship Behavior, Pakistan Journal of Commerce and Social Sciences 8.2, 453- 470 (2014)

32. Qingshan, H., Xuansheng, C., Le, L., Hua, H. Empirical Research on the Influence of Organizational Support on Psychological Capital, American Journal of Industrial and Business Management 4, 182-189 (2014)

33. Geoffrey, R.M., David, D., David, F. Essentials of Research Design and Methodology, Hoboken, NJ: John Wiley \& Sons. 1-306 (2005)

34. Maria, H. L. The Socio-Demographic Correlations of Psychological Capital, European Scientific Journal 9.29, 26-42 (2013)

35. Kathie, L. P., Michelle, C. B. Rebounding from Corruption: Perceptions of Ethics Program Effectiveness in a Public Sector Organization, Journal of Business Ethics 10, 551-566 (2006)

36. Weihui, Fu. The Impact of Emotional Intelligence, Organizational Commitment, and Job Satisfaction on Ethical Behavior of Chinese Employees, J Bus Ethics. 122.1, 137-144 (2013) 